\title{
ESTADO NACIONAL NO CONTEXTO
DA INTERNACIONALIZAÇÃo
}

\section{Roberto Freire}

- rocesso de in tegração é algo que acompanha a humanidade. Historicamente, o comércio tem sido um dos responsáveis por esse processo, como, por exemplo, no período das descobertas. Esse processo de integração tem se acelerado em função de mudanças concretas que se operam na relaçáo homem/ natureza, nas transformaçōes operadas na busca de progresso. As grandes revoluçōes não são assaltos ao poder. As grandes revoluçōes sāo mudanças efetivas na base do processo de produção. Quando da revolução industrial, o Estado nacional surgiu praticamente como conseqüência, já que revoluções, bem entendido como mudanças no processo e no modo de produzir, mudam relaçōes sociais e não apenas as de produção; mudam concepçōes, instituiçôes. Moldam novas concepçōes, novas instituiçōes. Este processo de internacionalização que estamos vivendo é fruto concreto da revolução industrial, e que caracterizase hoje como uma nova etapa de revolução cien tífico-tecnológica. $O$ modo de produzir, a riqueza de transformar a natureza como hoje ela se opera, cria inclusive novos

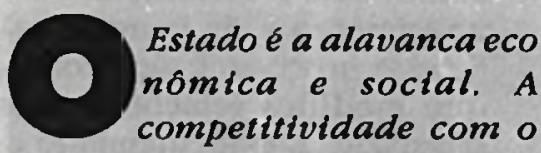

controle do Estado nas economias sociats é fundamental para a democracia. O mercado näo é livre e tem que sofrer regulação soctal. $\hat{E}$ prectso um Estado que tenha a efictência e a competência para nos tornar competitivos no processo de internacionalizaçäo. Nesse sentido, é necessário um projeto cufas caracteristicas respeite a realidade em que vivemos.

paradigmas e tem força suficiente para modificar esse modo de produzir, e pode até criar debates como esse. Nós estamos assistindo o início do fim - claro que dentro de grandes conflitos - do Estado nacional.

O nacionalismo exacerbado gera fascismo e é sempre ideologia de direita. Mas existiu o paradoxo: no processo de integração e de intemacionalizaçāo da economia, as economias periféricas viam o nacionalismo como algo que justificava muitas vezes posiçóes reformistas e até revolucionárias. 
Portanto, de esquerda. lisse processo conflituoso se acelera hoje de uma forma muito mais dramática em função do poder das comunicações. 'I'alvez até possamos dizer que começamos também o início de uma nova civilização. Não mais civilização industrial de trabalho, mas a civilização do conhecimento e da comunicação. Se esse processo é tão profundo que modifica relações e nossa consciência, evidentemente que modifica instituiçôes. Os estados supranacionais que hoje começam a existir por força da integração econômica, da globalização do mundo pela comun icação está criando a superação do con ceito de soberania e uma profunda transformação no seu conteúdo. Não é mais a soberania dos estados nacionais, mas a soberania de identidades nacionais que podem, num determinado momento, se afirmar além do seu território, junto a comunidade intemacional. Novos atores surgem, já nāo tendo mais limites de fronteira $e$ interferindo em soberanias de países nacionais. As Organizaçōes Não Govemamentais são uma demonstraçāo desse processo novo de participação numa crescente democratização da sociedade moderna. Tudo isso faz com que se percam alguns referenciais que a civilizaçāo industrial do trabalho postulava a respeito, inclusive do papel dos próprios partidos políticos. A crise que os partidos políticos enfrentam não é apenas brasileira. 'Talvez aconteça aqui de forma mais explicita, até porque nunca tivemos a civilização industrial do trabalho associada à democracia e, portanto, à formação de partidos.

Discutir o Istado nacional numa realidade que sempre se definiu bipolarmente, mesmo quando num mundo bipolar, tinha determinadas implicações ideológicas explícitas: de que lado se cstava. Apesar de que muitas vezes a esquerda não tivesse a clara compreensão de que o processo de auta rquização que o nacionalismo nos paises periféricos impunha não era algo que referendasse o scu isolamento, mas era um processo de luta que buscava a ruptura com o sistema que o in tegrava para integrar-se ao outro sistema, à outra organização social, ao outro bloco hegemônico do ponto de vista econômico, político e militar. İm nenhum momento alguém podia imaginar um processo de isolamento das suas cconomias, dos seus interesses, do seu território. O processo era um processo de integraçāo, só que bipolar que se exercia sob forma de ingerên cia direta e sem in tervençāo da comunidade internacional, até porque o poder de veto da ONU era oferecido a estes dois blocos. Nós fomos vítimas várias vezes de ingerência, como foram vítimas outros paises no bloco socialista. Hoje, numa outra relação, com o fim da guerra fria e a inexistência de blocos da bipolaridade, a realidade nos leva a repensar a questão dos interesses nacionais buscando identificá-los dentro dessa multipolaridade, dessa nova com- 
plexidade do mundo. E, portanto, buscar saber qual o papel desse Estado nacional. Porque continuamos a denominá-lo do mesmo modo, mas seu conteúdo, passando por profundas transformaçōes, certamente não será mais o mesmo.

Há algumas questōes que, quando são colocadas, de imediato nos levam a perceber as mudanças que começam a operar no conteúdo desse Estado. Um exemplo, quando se fala $\mathrm{cm}$ capital externo. $\mathrm{O}$ que se define como capital externo $\mathrm{cm}$ economias regionalizadas, de integração, como o MERCOSUL? Capital externo é aquele extemo à Argentina, ao Brasil, ao Uruguai, ao Paraguai? Como vamos tratar capital externo nas economias integradas da Europa Ocidental? Como vai se falar de capital extemo no NAFTA? Se esse fluxo começa a se dar não apenas pelo fluxo tradicional que se fazia com barreiras alfandegárias, com protecionismos, mas passa a ser feito a partir de processos de integração, de processo de accitaçâo e de assen timento? Como discutir conceitos que tinham a ver com fronteiras bem definidas, com barreiras econômicas explicitadas, com soberanias bem afirmadas, quando se dá a delegação de soberania, quando as fronteiras não mais existem, quando nāo se tem mais esse fluxo barrado por protecion ismos ou barreiras típicas de economias que se contrapunham? Esse novo papel do Estado é algo que precisa ser compreendido nes- sa nova realidade. Esse novo paradigma coloca a questão da democracia, hoje, como uma questão central, para qualquer tipo de ideologia política. Já não tem mais sentido nenhuma defesa de outro tipo de regime que não seja o da participação e da afirmação da cidadania. İm termos concretos, o próprio tema desse encontro é a tentativa de saber qual o Estado nacional brasileiro. O que nós temos é algo que foi de fundamental importância, inclusive naquilo que hoje se discute muito, que foi o seu papel de intervenção no processo econômico $\mathrm{e}$ indutor do desenvolvimento nacional. Esse papel pode mudar de conteúdo, mas continua sendo presente e não apenas no interesse nacional brasileiro, mas nos interesses nacionais de todos os países. Aqui foi dito e é verdadeiro: em nenhuma economia o papel do Estado foi diminuído. Ele pode ter sido mudado. E mudou. E o Brasil talvez esteja num momento $\mathrm{cm}$ que a mudança tem que se operar. É verdade que o Estado brasileiro foi responsável por esse país que não é Primeiro Mundo, mas também não é T'erceiro, embora tenha nâo só 'Terceiro, mas o Quarto e até o Quin to nas suas fronteiras, em termos da perversa realidade social. Mas, ao mesmo tempo, ele criou estruturas que o colocam, talvez, como um dos poucos paises que concretamente tem a oportunidade de participar desse processo da revolução científico-tecnológica. Essa capacidade que o Brasil adquiriu foi fruto de toda uma 
política cm que o Isstado foi a alavanca fundamental.

Na década de 40, o Brasil conseguiu, em função de contradiçōes internacionais, romper aquilo que era norma do imperialismo financeiro no mundo, nas relaçóes de fluxo de capital. O Brasil conseguiu implantar uma indústria de base - a siderurgia; construiu, no campo energético, a Petrobrás, a Fletrobrás; passou a investir decisivamente em infra-estrutura. Para termos alcançado a massa crítica profissional e tecnológica de que dispomos hoje o papel do Estado foi fundamental, inclusive para a formação de conglomerados e grupos de capitais nacionais - até porque grande parte dos nossos bens de capitais foram subsidiados ou diretamente construídos pelo Estado brasileiro. Isso gerou o país que nós temos.

Só que essa mudança que se opera no mundo, com a grande revoluçâo no modo de produzir, gerou problemas para países que conseguiram ter estados que alavancaram o desenvolvimento, criaram condiçōes dignas para a sua população, um Estado do bem-estar social. Exemplos concretos existem na Europa. No Brasil esse processo de desenvolvimento não gerou estruturas de bem-estar social. Ao contrário. Essa nova realidade levanta questôes fundamentais ainda sem dar respostas convincentes na Europa Ocidental, por exemplo, onde o processo de transformação de- semprega, onde o processo da revolução científico-tecnológico cria problemas para o próprio Estado do bem-estar social. É a grande discussão, hoje, na Europa, sobre o que fazer com aqueles que saem do mercado de trabalho e da produção industrial c que não têm espaço nem na área do serviço ou na área de lazer, não alcançam a plena ocupação, gerando aquilo que o Muro de Berlim separava como organização social. Hoje, os muros separam os pobres, porque não mais se precisa do exército industrial de reserva. Essa crise curopéia está sendo vivida tão gravemente que esquerda, em quase toda a Europa, vem sendo chamada para discutir o que fazer com essa massa de desempregados que não diminui mesmo com o aumento e a produção da riqueza como nunca foi visto - exemplo maior disso é a Espanha, com mais de $20 \%$ de sua força de trabalho desempregada, mas que foi um país que experimentou um grande crescimento. Nāo se tem idéia de como resolver esse problema mediante a intervenção do Estado, que é ou não a forma organizada c superior de qualquer sociedade?

No Brasil, temos que enfrentar essa terceira revolução industrial - da ciência e da tecnologia - para sermos contemporâneos desse futuro num Estado que não cumpriu com as suas obrigaçooes mínimas durante o processo de industrialização e de crescimento. Vamos enfrentar problemas que nos colocam no Primeiro Mundo, quando 
estamos precisando também enfrentar aquilo que nos remete ao Quinto ou ao Sexto.

E isso não pode ser feito com a ausência do Estado, com Estado mín imo, com essa visāo neoliberal em que discute tamanho de Estado. Eu quero discutir não é tamanho, cu quero discutir é eficiência. Eu quero discutir quais os objetivos, e esses objetivos têm que ser definidos pela cidadania. O momento concreto de discutir no Brasil qual o papel do Estado é esse. 'Temos que ter, por um lado, a continuação do processo de desen volvimento, da capacidade de nos inserirmos nessa revoluçāo, de sermos contemporâneos; c por outro, precisamos de um Estado que tenha a capacidade de fazer as transformações sociais para superar a perversa desigualdade que existe na sociedade brasileira. Esse duplo papel do Fstado tem que ser agora formulado.

Está se discutindo o papel do Estado na economia. Eu falei da siderungia. Podemos falar em vários outros momentos em que o Estado brasileiro fez interven ção concreta. Talvez não seja mais o momento de imaginarmos o Estado brasileiro investindo $\mathrm{cm}$ siderurgia, até porque novos materiais deixam a siderurgia para países periféricos. Mas o Estado tem um papel importante exatamente em relação aos novos materiais. O Estado tem um papel a desempenhar na formação, na educaçāo, na qualificaçāo da sua populaçāo. Porque aí é como vai se qualificar pela competitividade, se integrar, se internacionalizar de acordo com seus interesses. É irreversivel a intemacionalização. O que o Estado brasileiro tem que, talvez, discutir, é que não cabe mais a sua intervenção no aço, mas nas novas tecnologias de ponta, especial, dos novos materiais, da eletrônica e, fundamentalmente, naquilo que é futuro, a biotecnologia. E sem Estado, tal como na década de 40 , não vamos criar a alavanca para esse processo. Não vão ser capitais privados, porque os nacionais não tĉm capacitação, tal como não tinham em 40 para montar nossas siderurgias, nem capital externo, até porque esse processo de intemacionalizaçāo não deixa de ser processos de subordinaçāo, de colonizaçāo.

Essa discussão passa até pelas menores coisas. Nós estamos enfrentando uma questão da revisão, que eu não sei se já foi enterrada. E o centro da discussão talvez tenha sido exatamente o papel do Estado. E se discutiu mal, se discutiu ideologicamente, tal como se usa a privatização de forma ideológica. Embora alguns setores ten ham tentado tirar a ideologia ela está muito presente, e não está apenas na esquerda, que nāo fez revisāo, ela está na direita que quer continuar mantendo a exclusão. Nós temos que discutir é o papel que o Estado brasileiro tem que desempenhar nesse processo de transformação imposto pela intemacionalização, resultante da 
integração e da globalização provocadas pelos meios de comunicação. Nós estamos vivendo um momento em que ele terá condiçōes de se expandir e de se aprofundar, que é o processo eleitoral que se avizinha. Nāo podemos fugir da discussão de saber que talvez o monopólio da Petrobrás deva continuar, até porque esse setor é cartelizado. Isso não é um setor de competitividade ou de concorrência. E não é porque a Petrobrás pode nāo ter tido competência, por exemplo, no corporativismo e tenha tido grande competência no setor tecnológico, ou porque não tenha atendido o seu objetivo para o qual foi criada, de ter auto-suficiência em petróleo. ĺ. porque este é um setor que depende ainda de um Estado para evitar que ele possa ser cartelizado por outros interesses que não sejam os nacionais. Da mesma forma as telecomunicaçōes. Atć porque o nosso monopólio é atípico. Não é um monopólio de comunicações em geral, tal como existia na Europa, na Inglaterra mesmo, que hoje, é interessante notar, banca toda a sua onda neoliberal. Aqui, nós sempre tivemos um monopólio atípico, que era apenas de alguns setores, enquanto outros era predominantemente da iniciativa privada, por con cessão - as comunicaçōes sociais. E é importante que assim seja, c é importante que continue, até como monopólio atípico, por uma questāo básica que é a questão democrática. É um setor também cartelizado no mundo, intenso de capital e que não pode se imaginar a formação de monopólios privados. Se o monopólio estatal nas comunicaçōes, quando foi geral, gerou distorçōes que hoje reconhecemos - apesar de que durante muito tempo nós comunistas defendíamos a estatização completa de todas as comunicaçóes, particularmente as comunicaçóes sociais - estamos vendo que competitividade dada pelo Estado e com controle da sociedade é algo fundamental para a democracia. I:, portanto, a permanência do monopólio se faz necessária. Mesmo que con tinue atípico, podendo fazer concessóes para outros setores, mas com esse con trole social que é essencial. Até porque ao se falar em economia de mercado é bom que se tenha também presente que mercado não é livre. Isso é fetiche. Mercado tem que sofrer regulação social, por conta dos monopólios, dos cartéis, dos oligopólios, por conta das subordinações internacionais, por conta dos interesses nacionais. lisse processo de discussão engatinha porque a ideologia presente ainda é forte o suficiente para que a esquerda, inclusive a brasileira, ainda nāo tenha feito toda a sua reciclagem. Alguns ainda pensam que o Muro não caiu. I: eles precisam saber que caiu cm cima da gente. O que imaginávamos é que cairia em cima do capitalismo, já que a organização social socialista cra algo superior, e ela foi a primeira vítima dessa revolução científica-tecnológica. A incapacidade 
do Estado socialista de acompanhar essa revolução - acompanhava somente por conta da guerra fria, investindo $\mathrm{cm}$ tecnologia militar sem fazer a mediação com a sua cidadania - gerou o seu esgotamento e a sua derrocada. E a primeira vítima, como a segunda vítima, cstão sendo os países do capitalismo industrial que não conseguem dar esse salto que estão vendo fugir a sua hegemonia. Isto é algo tremendamente positivo. Precisamos falar em estatização da saúde e da educaçāo. Porque no Brasil não se criou esse Listado do bem-estar social e nós temos as maiores perversidades. E, talvez, sejamos beneficiários dela, enquanto parcela da população que pode escamotear os serviços do Estado relativos à saúde e à educação. Porque há muito tempo prescindimos de um Estado para gerir essas atividades, que são fundamentais para a própria dignidade do individuo. $\mathbf{A}$ maioria da população precisa do Esstado para isso. Nós não, só queremos o Estado quando cstamos discutindo as mensalidades escolares ou os planos de saúde com as suas exorbitancias c scus abusivos aumentos. Ai é Estado. Embora, possamos ter até como discurso a fala de que queremos a escola pública, de que queremos a saúde pública mas esse discurso é retórico. Porque nossa prática é colocar nossas bandeiras em lutas pelas mensalidades. Não temos bandeira alguma quando se discute a escola pública.
Esse processo de privatização do Estado é algo que precisa ser enfrentado, tomando-o público naquilo que é cssencial, nāo esquecendo do seu papel de alavancagem no processo de indução do crescimento. É importante ajustar esses dois momentos, imaginar o processo que se avizinha e a necessidade de uma reforma democrática do Estado para que o país tenha capacidade do bem-estar. Não estou tentando recuperar ou resgatar nenhum projeto social-democrata dos tradicionais anos $\mathbf{3 0}$ ou $\mathbf{4 0}$ da Europa, mas um projeto social-democrata, ou o nome que se queria dar, para o Brasil desse limiar do século XXI. Projeto cujas características respeite a realidade em que nós vivemos. Enfim, um Estado que tenha a eficiência, a competência para nos tomar competitivos no processo de internacionalização.

Resumen

EL ESTADO NACIONAL EN EL CONTEXTO DE LA INTERNACIONALIZACIÓN

El Estado es la palanca cconómica y social. La competitividad con el control del Estado en las economias sociales es fundamental para la democracia. Eil mercado no es libre y tiene que sufrir 
regulación social. Es necesario un Estado que tenga la eficiencia y la competencia para hacemos competitivos en el proceso de intemcionalización. En ese sentido, es necesario un proyecto cuyas caracteristicas respeten la realidad en que vivimos.

\section{Abstract \\ THE NATIONAL STATE IN THE \\ CONTEXT OF \\ INTERNATIONALIZATION \\ PROCESS}

The State is the economic and social lever. Market efficiency with the State control is fundamental for democracy. The market isn't free and must suffer social regulamentation. A State that has efficiency and competence is necessary to make the economy competitive in the internationalization process. In this sence, a project - with characteristics that respect the reality in which we live - is necessary.
Texto baseado em palestra proferida durante o Encontro Nacional: Funçāo Pública, Estado e Socicda. de, realizado na ENAP, Brasilia/DF, em abril de 1994.

Roberto Freire é senador pelo PPS/PE. 